\title{
POUZDANOST PROCJENE PRISUSUSTVA LIMFOVASKULARNE INVAZIJE KOD PLUĆNOG ADENOKARCINOMA NA OSNOVU PREOPERATIVNE VELIČINE TUMORA
}

\author{
RELIABILITY OF LYMPHOVASCULAR INVASION ASSESSMENTS IN PULMONARY \\ ADENOCARCINOMA BASED ON THE PREOPERATIVE TUMOR SIZE
}

\author{
Kemal Grbić, Mirko Stanetić, Slavko Grbić
}

\begin{abstract}
Sažetak:
U trenutno važećoj klasifikaciji tumora pluća uveden je pojam "invazivnog adenokarcinoma”

prema stepenu agresivnosti istog. Prisustvo limfovaskularne invazije u tumoru je jedan od takvih atributa i parametar je očekivano lošeg toka bolesti. Cilja rada je procjeniti prisustvo limfovaskularne invazije kod plućnog adenokarcinoma na osnovu preoperativne veličine tumora. Materijal i metode: $U$ istraživanje je uključen 261 pacijent operativno tertiran zbog dokazanog adenokarcinoma pluća. U istraživanje su uključeni samo pacijenti sa decidnom preoperativnomveličinom tumora (cT=mm.) $i$ limfovaskularnim statusom (LVI) u plućnom resektatu. Rezultati: Prisutnost LVI, spolna distribucija, distribucija veličine tumora detreminirana CT-om, te starosna dob između muških $i$ ženskih ispitanika u ispitivanom uzorku bila je statistički signifikantna $(p<0,05)$. Veličina tumora se pokazala kao značajan marker pojave LVI u resektatu sa senzitivnošću od 90,9\%, specifičnosti 93,5\%; PPV =97,8\%; NPV = 76,3\%. Cut off vrijednost veličine tumora je iznosila 4,5 cm, a AUK=0,945 (IP 0,905-0,985; $p<0.001)$ Logističkom regresijom je utvrđeno da je preoperativna veličina tumora nezavisni pozitivni prediktor pojave limfovaskularne invazije kod adenokarcinoma pluća $(O R=7,302 ; I P=4,303-12,392)$. Zaključak: Preoperativne veličina tumora je statistički značajan marker pojave limfovaskulaarne invazije kod plućnog adenokarcinoma.
\end{abstract}

Ključne riječi: adenokarcinom pluća, veličina tumora, limfovaskularna invazija

\section{UVOD}

Prema posljednim onkološkim statističkim izvještajima nemikorcelularni karcinom pluća (Non Small-Cell Lung Cancer - NSCLC) je vodeći uzrok morbiditeta $(11,6 \%)$ i mortaliteta $(18,4 \%)$ među svim malignim oboljenjima u svijetu (1). Pri tome, najupadljiviji je rast učestalosti adenokarcinoma, koji u zadnjih 10 godina bilježi $40-45 \%$ novootkrivenih slučajeva, te je procentualno daleko ispred tumora porijekla pločastog epitela, a koji su ranije bili vodeći u grupi primarnih plućnih neoplazmi $(2-4)$.

Adenokarcinomi predstavljaju spororastuće, periferno lokalizovane tumore, sa zonama kavitacije i nekroze, a karakterizirani su dugim asimptomatskim vremenskim periodom, kasnom dijagnostikom, ranim metastazama i lošom prognozom u smislu čestih recidiva, čestih relapsa $\mathrm{i}$ kratkog preživljavanja $(2,5)$. Najčešća mjesta sekundarnih depozita su koštani i centralni nervni sistem, jetra i plućni parenhim $(6,7,8)$. Stopa sveukupnog petogodišnjeg preživljavanja je svega $13-18 \%(2)$.

Prisustvo limfovaskularne invazije (LVI) u tumoru predstavlja negativan prognostički faktor i prediktor je lošeg terapijskog toka i ishoda bolesti, a što je zaključak velikog broja dosadašnjih istraživanja $(10,11,12)$. Navedeni parametar je sadržan u trenutno važenoj patohistološkoj klasifikaciji, gdje se prvi put uvodi naziv „,invazivnog adenokarcinoma“, subluksiran na dominantne histološke tipove prema stepenu agresivnosti (13).

Preoperativna veličina tumora (cT - deskriptor) je dio TNM stejdžinga, te je takođe važan atribut uniformnog dijagnostičko-terapijskog i prognostičkog toka bolesti (14). Mada je dokazana korelacije preoperativne veličine i statusa limfovaskularne invazije $(15,16)$, nije poznato pri 
kojoj preoperativnoj veličini tumora možemo očekivati pojavu limfovaskularne invazije u tumoru.

\section{CILJ RADA}

Cilj rada je procjeniti sa kojim stepenom statističke sigurnosti i pri kojoj preoperativnoj veličini tumora možemo očekivati pojavu limfovaskularne u plućnim resektatima kod adenokarcinoma pluća.

\section{MATERIJAL I METODE RADA}

U statističku analizu koja predstavlja presječnu studiju je uključen 261 pacijent operativno tretiran zbog dokazanom adenokarcinoma pluća svih patohistoloških dominacija. U studiju su uključeni samo pacijenti koji su imali decidno verificiranu veličinu tumora preoperativno, te u definitivnom patohistološkom izvještaju plućnog resektata opisan status limfovaskularne invazije.

Preoperativna veličina tumora (cT) je određena na višeslojnom CT (MSCT) aparatu marke GE LightSpeed VCT sa 64 reda detektora (General Electric Company, Fairfield, Connecticut, USA) u nativnoj i kontrastnoj (Ultravist 370, Schering, Germany) seriji u slojevima od po $0,625 \mathrm{~mm}$. Veličina tumora je od strane torakalnog radiologa mjerena $u$ tri ravni tj. izmjereni su anteroposteriorni, laterolateralni i kraniokaudalni dijametar, od kojih je za ovo istraživanje uzeta najveća mjera izražena u milimetrima $(\mathrm{mm})$.

Plućni resektat je fiksiran u 10\% puferisanom formalinu u trajanju do 24 sata. Potom je dehidriran $\mathrm{u}$ alkoholu rastuće koncentracije, prosvjetljen $\mathrm{u}$ hloroformu, kalupljen u odgovarajuće parafinske blokove, rezan na kliznom mikrotomu na debljinu 4-5 mikrona, deparafiniziran i bojen standardnim (hematoxylin-eosin) bojenjem, te analiziran od strane patologa. U patohistološkom nalaza status limfovaskularne invazije u tumoru je opisan kao LVI+ (limfovaskularna invazija prisutna) i LVI(limfovaskularne invazije nema).

\section{Statistička obrada podataka}

Podaci su prikazani kao medijana i interkvartilni interval (IQR). Distribucija podataka je analizirana Shapiro -Wilk i Kruskall-Walls ili Mann-Whitney U testom. Povezanost između kontiniranih varijabli je testirana pomoću Spearmanove korelacione analize. Specifičnosst i senzitivnost tumora kao faktor pouzdanosti prisustva limfovaskularne invazije je testiran pomoću ROC-krive. Urađena je binarna logistička regresija kako bi se pokazalo da promjena veličine tumora može utjecati na LVI status. Zadani nivo statističke značajnosti je $p<0,05$.

\section{REZULTATI}

Numerički i procentualni udio, te statistička značajnost posmatranih parametara su prikazani $\mathrm{u}$ tabeli 1.

Tabela 1. Karakteristike, udio i statistička značajnost posmatranih parametara

\begin{tabular}{|c|c|}
\hline $\begin{array}{l}\text { Posmatrani parametri } \\
\text { Udio }(\mathrm{N}, \%)\end{array}$ & $\mathrm{p}$ - vrijednost \\
\hline $\begin{array}{l}\text { Spol } \\
\text { Muškarci } \\
166(63,60 \%) \\
\text { Žene } \\
95(36,40 \%)\end{array}$ & $<0,001$ \\
\hline $\begin{array}{l}\text { Starost (godine) } \\
\text { Muškarci } \\
63 \pm 1,6 \text { Žene } \\
62 \pm 2,4\end{array}$ & $=0,022$ \\
\hline $\begin{array}{c}\text { Veličina tumora (cT) } \\
\text { cT1b } \\
13(4,98 \%) \\
\text { cT1c } \\
30(11,69 \%) \\
\text { cT2a } \\
33(12,64 \%) \\
\text { cT2b } \\
43(16,75 \%) \\
\text { cT3 } \\
107(40,99 \%) \\
\text { cT4 } \\
35(13,40 \%)\end{array}$ & $<0,001$ \\
\hline $\begin{array}{l}\text { Limfovaskularna invazija (LVI) } \\
\text { Prisutna (LVI+) } \\
199(76,24 \%) \\
\text { Nema (LVI -) } \\
62(23,76 \%)\end{array}$ & $<0,001$ \\
\hline
\end{tabular}

Od 261 ispitanika uključenih u istraživanje 166 $(63,60 \%)$ su bili muškog, a $95(36,40)$ ženskog spola, te statistički posmatrano postoji značajnost razlika udjela oboljelih prema spolnoj strukturi $(\mathrm{p}<$ $0,001)$. Prosječna starost osoba muškog $(63 \pm 1,6)$ i ženskog spola $(62 \pm 2,4)$ takođe ima ststističku signifikatnost $(\mathrm{p}=0,022)$. 
$\mathrm{U}$ posmatranom uzorku nije bilo tumora preoperativne veličine do i $1 \mathrm{~cm}$. (cT1a). Najmanje je zastupljen cT1b descriptor sa udjelom 4,98\% $(13 / 261)$, parametri c(T1c, T2a i cT4) su sa skoro identičnim udjelom, a najviša frekvenca je parametra cT3 od 41\%(107/261), što daje statističku značajnost posmatranom parametru $(\mathrm{p}<0,001)$. Znatno veća prisutnost limfovaskularne invazije [76,24\%; (199/261)], u odnosu na njeno nepostojanje u tumoru $[23,76 \% ;(62 / 261)]$, je takođe statistički signifikantno $(\mathrm{p}<0,001)$.

Pouzdanost veličine tumora kao markera pojave limfovaskularne invazije kod adenokarcinoma pluća je prikazana na grafikonu 1 .

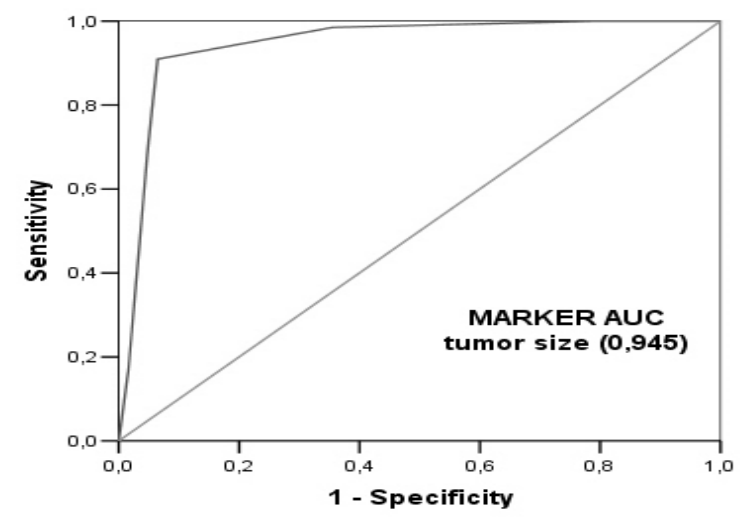

AUC-area under curve (površina ispod krive)

Grafikon 1. Senzitivnost i specifičnost preoperativne veličine tumora kao potencijalnog markera pojave limfovaskularne invazije kod adenokarcinoma pluća

\begin{tabular}{|l|l|l|l|l|l|l|l|}
\hline Varijabla & Area & $\begin{array}{l}\text { Senzitiv } \\
\text { nost } \\
(\%)\end{array}$ & $\begin{array}{l}\text { Specifič } \\
\text { nost } \\
(\%)\end{array}$ & $\begin{array}{l}\text { PP } \\
(\%)\end{array}$ & $\begin{array}{l}\text { NP } \\
(\%)\end{array}$ & IP & $\mathrm{p}<$ \\
\hline $\begin{array}{l}\text { Tumor } \\
\text { size } \\
\text { (cm.) } \\
\text { (cut off }- \\
4,5)\end{array}$ & $\begin{array}{l}0,94 \\
5\end{array}$ & $90,9 \%$ & $93,5 \%$ & $\begin{array}{l}97,8 \\
\%\end{array}$ & $\begin{array}{l}76,3 \\
\%\end{array}$ & 0,985 & \\
\hline
\end{tabular}

PP - pozitivna prediktivnost; NP - negativna prediktivost; IP interval pouzdanosti; $p$ - vrijednost

Senzitivnost za veličinu tumora iznosila je $90,9 \%$, specifičnost $93,5 \%$, pozitivna prediktivnost $97,8 \%$, a negativna prediktivnost $76,3 \%$ AUC za veličinu tumora iznosila je 0,945 , dok cut off vrijednost $4,5 \mathrm{~cm}$.

Binarnom logističkom regresijom utvrđeno je da je preoperativna veličina tumora nezavisni pozitivni prediktor pojave limfovaskularne invazije kod adenokarcinoma pluća $\quad(\mathrm{OR}=7,302 ; \quad \mathrm{IP}=4,303$ 12,392).

\section{DISKUSIJA}

Prisustvo limfovaskularne invazije od 76,24 \% u ukupnom broju reseciranih uzoraka naše posmatrane grupe, korelira sa izvještajima trenutno važeće patohistološke klasifikacije tumora gdje je taj udio 70-90\% (13). Razlog da smo u našim rezultatima imali najviše tumora preoperativne veličine od 5-( i) $7 \mathrm{~cm}$., a što prema važećoj TNM klasifikaciji odgovara cT3 deskriptoru, možemo pravdati u uvodu pomenutom toku i detekciji bolesti $u$ odmaklom stadiju $(2,5,14)$.

Da je pojava limfovaskularne invazije u tumoru parametar očekivano lošeg toka bolesti pokazao je veliki broj istraživanja koji su tretirali ovu problematiku. Mollberg i saradnici su u svom multicentričnomm istraživanju koja je uključivalo 131 studiju iz raznih zemalja, pokazali znatno lošiji period bez recidiva i relapsa, te kraće ukupno preživljavnje kod pacijenata koji su u tumoru imali limfovaskularnu invaziju, u odnosu na one koji nisu (10).

Sung i kolege su u svojoj studiji imali 381 oboljelih stadija T1-2N0, podvrgnutih kompletnoj resekciji i adjuvantnom tretmanu. Pacijenti sa limfovaskularnom invazijom $\mathrm{u}$ tumoru su imali lošiji period bez progresije bolesti $(43,7 \%$ vs. $74,4 \%)$, češću pojavu N1 i N2 metastaza (22,5\% vs. $8,7)$, te češće udaljenu bolest $(30,4 \%$ vs. $14,9 \%)$ (11). Okiror je prateći 514 kompletno liječenih pacijenata, našao više nodalnih metastaza i imao kraće sveukupnom preživljavanje kod ispitanika sa prisutnom LVI u resektatu (12).

Kako smo zadali u ciljevima ovog istraživanja, a prikazali ROC (Receiver Operating Characteristic) analizom (grafikon 1.), utvrđena cut-off vrijednost veličine tumora od $4,5 \mathrm{~cm}$. kao prognostičkog markera pojave limfovaskularne invazije kod plućnog adenokarcinoma, pokazuje senzitivnost od 90,9 \% i specifičnost 93,5\% (PPV 97,8\%; NPV 76,3\%). Površina ispod ROC krive je 0,945 (IP 0,905-0,985: $\mathrm{p}<0,001) \quad[\mathrm{OR}=7,302 ; \mathrm{IP}=4,303-$ $12,392]$. 


\section{ZAKLJUČAK}

$\mathrm{Na}$ osnovu urađenog istraživanja i statističke obrade podataka možemo zaključiti, da sa visokom stepenom senzitiviteta i specificiteta preoperativna veličine tumora može biti pouzdan marker postojanja limfovaskularne invazije kod plućnog adenokarcinoma..

\section{LITERATURA}

1. Bray F, Ferlay J, Soerjomataram I, Siegel RL, Torre LA, Jemal A. Global cancer statistics 2018: GLOBOCAN estimates of incidence and mortality worldwide for 36 cancers in 185 countries. CA Cancer J Clin. 2018;68(6):394-424.

2. American Cancer Society, Cancer Facts \& Figures 2018.

http://www.cancer.org/acs/groups/content/@research /documents/webcontent/acspc-042151.pdf.

Pristupljeno: mart 2019.

3. Robert Koch-Institut und die Gesellschaft der epidemiologischen Krebsregister in Deutschland e.V. Krebs in Deutschland 2013/2014;10. Ausgabe, Berlin 2015.

4. https://eliph.klinikum.uni-

heidelberg.de/texte_s/651/bronchialkarzinom.Pristup ljeno:mart 2017.

5. Travis WD. Reporting lung cancer pathologal specimens. Impact of the anticipated 7th Edition TNM Classification based on recommendation of the IASLC Staging Committee. Histopathology. 2009; 54(1): 3-11.

6. Helmut H. Popper. Progression and metastasis of lung cancer. Cancer Metastais Rev. 2016; 35: 75-79.

7. Matias Riihimaki, Hauke Thomsen, Kristina Sundquist, Jan Sundquist, Kari Hemminiki. Clinicall landscape of cancer metastases. Cancer Med. 2018; 7(11): 5534-5542.

8. Tamura T., Kurishima K., Nakazawa K., Kagohashi K., Ishikawa H., Satoh H. Specific organ metastases and survival in metastatic non-cmall-cell lung cancer. Molecular and Clinical Oncology. 2015; 3: 217-221.

9. William D. Travis, MD, Elisabeth Brambilla, MD, Masayuki Noguchi, MD, Andrew G, Nicholson, MD, Kim R. Geisinger, MD, Yasushi Yatabe, et al. International Association for the Study of Lung Cancer, J Thorac Oncol. 2011; 6(2): 244-285.

10. Mollberg NM, Bennette $\mathrm{C}$ et al. Lymphovascular invasion as a prognostic indicator in stage I nonsmall cell lung cancer: a systemic review and metaanalysis. Ann Thorac Surg. 2014; 97(3): 965-971.

11. Sung SY, Kwak YK, Lee SW, Jo IY, Park JK, Kim KS, Lee KY, Kim $\quad$ YS. Lymphovascular Invasion Increases the Risk of Nodal and Distant Recurrence in Node-Negative Stage I-IIA Non-Small-Cell Lung Cancer. Oncology 2018; 30:1-7.

12. Okiror L, Harling L, Toufektzian L, King J, Routledge T, Harrison-Phipps K. Prognostic factors including lymphovascular invasion on survival for resected non-small cell lung cancer, J Thorac Cardiovasc Surg. 2018; 156(2): 785-793.

13. W. D.Travis, MD, E. Brambilla, MD, A. G. Nicholson, MD et al. The 2015 World Healt OrganizationClassification of Lung Tumors Impact of Genetic, Clinical and Radiologic Advances Since the 2004 Classification. J. Thorac Oncol. 2015; 10: 1243-1260.

14. Rami-Porta R, Bolejack V, Crowley J, Ball D, Kim J, Lyons G, et al. The IASLC Lung Cancer Staging Project: Proposals for the Revisions of the $T$ Descriptors in the Forthcoming Eighth Edition of the TNM Classification for Lung Cancer. J Thorac Oncol. 2015; 10(7): 990-1003.

15. Wang S, Zhang B, Qian J, Qiao R, Xu J, Zhang L, Zhao $\mathrm{Y}$ et al. Proposal on incorporating lymphovascular invasion as a T-descriptor for stage I lung cancer. Lung Cancer 2018; 2018: 245-252.

16. Park C, In Lee IJ, Jang SH, Lee JW. Factors affecting tumor recurrence after curative surgery for NSCLC: impacts of lymphovascular invasion on early tumor recurrence. J Thorac Dis. 2014; 6(10); $1420-1428$.

\section{Summary:}

In the currently valid classification of lung tumors, the term "invasive adenocarcinoma" was introduced, according to the degree of its aggression. The presence of lymphovascular invasion in the tumor is one of such attributes and the parameter of an expected bad disease outcome.

The aim of the study is to assess lymphovascular invasion in pulmonary adenocarcinoma based on the preoperative tumor size Materials and methods: The study involved 261 patients who were operatively treated because proven presence of lung adenocarcinoma. Only patients with preoperatively accurately assessed tumor size $(c T=\mathrm{mm}$.) and specified lymphovascular status in the pulmonary 
resectate (LVI) were involved in the study. Results: LVI presence, sex distribution, tumor size distribution determined by $C T$, and age between male and female subjects in the examined sample were statistically significant $(p<0.05)$. The tumor size was shown to be a significant LVI marker with a sensitivity of $90.9 \%$, specificity of $93.5 \% ; P P V=97.8 \%$; NPV $=76.3 \%$. The cut-off value of the tumor size was $4.5 \mathrm{~cm}$ and $A U C=0.945$ (IP 0.905-0.985; $p<0.001)$. Logistic regression showed that preoperative tumor size was an independent positive predictor of lymphovascular invasion in lung adenocarcinoma $(O R=7,302$; $I P=4,303-12,392)$. Conclusion: Preoperative tumor size is a statistically significant marker of lymphovascular invasion in pulmonary adenocarcinoma.

Key words: lung adenocarcinoma, tumor size, lymphovascular invasion

Corresponding author:

Kemal Grbić

Clinic for Thoracic Surgery, Clinical Center University of Sarajevo

Bolnička 25. 71000 Sarajevo, Bosnia and Herzegovina

Tel. 061790 994, 033297238

E-mail: kemalgrbic@hotmail.com 